\title{
Effects of entorhinal cortex lesions on memory in different tasks
}

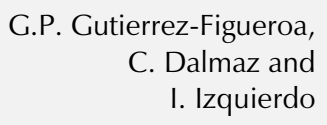

\author{
Centro de Memória, Departamento de Bioquímica, \\ Instituto de Ciências Básicas da Saúde, \\ Universidade Federal do Rio Grande do Sul, \\ 90035-003 Porto Alegre, RS, Brasil
}

\author{
Correspondence \\ C. Dalmaz \\ Centro de Memória \\ Departamento de Bioquímica \\ Instituto de Ciências Básicas da \\ Saúde, UFRGS \\ Rua Ramiro Barcellos, 2600 \\ 90035-003 Porto Alegre, RS \\ Brasil \\ Fax: 55 (051) 316-3505 \\ Research supported by FINEP. \\ G.P. Gutierrez-Figueroa is a \\ visiting fellow from the \\ University of Quito, Ecuador. \\ $\ldots \ldots \ldots \ldots \ldots \ldots$
}

\begin{abstract}
Lesions of the entorhinal cortex produce retrograde memory impairment in both animals and humans. Here we report the effects of bilateral entorhinal cortex lesions caused by the stereotaxic infusion of $\mathrm{N}$-methyl-D-aspartate (NMDA) in rats at two different moments, before or after the training session, on memory of different tasks: twoway shuttle avoidance, inhibitory avoidance and habituation to an open field. Pre- or post-training entorhinal cortex lesions caused an impairment of performance in the shuttle avoidance task, which agrees with the previously described role of this area in the processing of memories acquired in successive sessions. In the inhibitory avoidance task, only the post-training lesions had an effect (amnesia). No effect was observed on the open field task. The findings suggest that the role of the entorhinal cortex in memory processing is task-dependent, perhaps related to the complexity of each task.
\end{abstract}

Key words

- Entorhinal cortex

- Memory

- NMDA lesions

\section{.................. Introduction}

The entorhinal cortex is superficial to the amygdala, forming the anterior part of the parahippocampal gyrus (1). It processes different types of memories, including aversive and spatial memories (2-4) both in rats $(2,5,6)$ and primates $(3,7)$. In humans, the most prominent lesions of Alzheimer's disease are found in the entorhinal cortex $(1,8)$.

The entorhinal cortex has two-way monoand polysynaptic connections with the amygdala, the hippocampus and the medial septum (9), structures known to be involved in the processing of memories (10). Thus, the entorhinal cortex has been suggested to be an area for the integration of information previously processed by the amygdala, hippocampus and/or septum and for the distribution of this information to other parts of the brain $(1,10)$. Experiments using infusion of selective neurotransmitter receptor agonists and antagonists into the entorhinal cortex at different times after training and at the time of testing suggest that this structure has a delayed posttraining role in memory $(4,10)$ particularly in the integration or summation of memories acquired in consecutive trials or episodes (11).

The present study investigated the effect on memory of bilateral stereotaxic N-methyl-Daspartate (NMDA) lesions made either before or after the acquisition of different tasks. 


\section{Material and Methods}

\section{Subjects}

Male adult Wistar rats (90-120 days, weighing 230-270 g) from our breeding stock were housed in groups of 4 animals per cage and kept under a normal 12-h dark/light cycle with food and water ad libitum.

\section{Surgical procedures}

The animals were anesthetized with Thionembutal (thiopental sodium, $40 \mathrm{mg} /$ $\mathrm{kg}, i p$ ), and placed in a stereotaxic apparatus. The needle (31 gauge) connected to a Hamilton syringe $(5 \mu \mathrm{l})$ and attached to the stereotaxic injector was gently lowered into the entorhinal cortex through a skull hole using the following coordinates (bregma system), according to the atlas of Paxinos and Watson (12): $\mathrm{AP}=-0.67 \mathrm{~cm}, \mathrm{LL}=+0.50 \mathrm{~cm}$, and DV $=-0.58 \mathrm{~cm}$ from the dura mater, with the nosebar at $-0.33 \mathrm{~cm}$ from the interaural line. A bilateral infusion $(0.5 \mu \mathrm{l} / \mathrm{structure})$ of $10 \mathrm{mg} / \mathrm{ml} \mathrm{NMDA}$ was manually delivered for $2 \mathrm{~min}$, for a total dose of $5 \mu \mathrm{g}$ per structure. The needle was withdrawn slowly after 5 min $(13,14)$. Immediately after surgery the animals received an intramuscular injection of penicillin. The animals were allowed to recover for 1 week before being submitted to the behavioral tasks (training and testing, in the case of pretraining lesion) or to the test session (post-training lesion). Control animals were injected with saline.

\section{Behavioral procedures}

Step-down inhibitory avoidance. The animals were trained and tested for the oneway step-down inhibitory task using a $50 \mathrm{x}$ $25 \times 25-\mathrm{cm}$ plywood box with a glass-wall front and a floor consisting of 1-mm bronze bars spaced $10 \mathrm{~mm}$ apart (15). The left end of the grid was covered with a 5-cm high, 25$\mathrm{cm}$ wide, and $7.5-\mathrm{cm}$ long wood platform.
During the training trial, the animals were gently held by their bodies and lowered onto the platform with their noses pointing to the left corner, when a timer was activated. The timer measured the latency to step down (i.e., all four paws on the grid) when an intermittent footshock $(0.5 \mathrm{~mA}, 60 \mathrm{~Hz})$ was delivered until the animal climbed back onto the platform. In the test session, the animals were again placed on the platform. No footshock was given in the testing session. A 300 -s ceiling was imposed on testing session latency measurements; latencies $\geq 300$ s were counted as 300 s. Differences in testingtraining session latencies were used as retention scores.

Two-way active avoidance. The animals were trained and tested in a two-way active avoidance task in an automatic $50 \times 25 \times 25$ $\mathrm{cm}$ opaque acrylic shuttle-box whose floor was a grid of bronze bars $1 \mathrm{~mm}$ in diameter spaced $10 \mathrm{~mm}$ apart (16). Both the training and the test sessions consisted of 30-tone footshock trials preceded by 3 -min free exploration of the shuttle-box, with no stimulation. In each session, the intertrial interval varied at random from 10 to $50 \mathrm{~s}$. Each 7-s tone was immediately followed by a $0.5-\mathrm{mA}$ footshock delivered until the animals crossed the midline. The shock was omitted if the animals crossed to the opposite side of the grid during the tone (avoidance response). The difference in the avoidance responses between the test and the training trials was used as the measure of retention $(17,18)$.

Habituation to an open field. A 50-cm high, $40 \times 60-\mathrm{cm}$ open field made of brown plywood with a frontal glass wall was used (15). The floor was subdivided into 12 equal $13.3 \times 15.0-\mathrm{cm}$ rectangles delimited by white lines. Both in the training and in the test sessions, the animals were gently placed facing the left corner and allowed to explore the arena for $3 \mathrm{~min}$. Rearings and line crossings were counted in both sessions. The difference in the number of rearings and crossings between the test and the training trials was 
used as the measure of retention.

\section{Histological analysis}

After the behavioral studies, exact placement of the site of injection (lesion) was determined histologically. The rats were anesthetized with an overdose of Thionembutal and perfused with saline solution followed by $10 \%$ formaldehyde solution. Slices were stained with hematoxylin-eosin. The location of the lesion is shown in Figure 1. Behavioral data from only the animals with the lesion located in the intended site were used.

\section{Experimental design}

In each experiment the rats were randomly assigned to the different experimental groups.

In Experiment 1, the animals were submitted to the surgical procedures. After one week for recovery, lesioned and control rats were submitted to only one behavioral task: step-down inhibitory avoidance, two-way active avoidance or habituation to the open field.

In Experiment 2, the animals were divided into three groups, and each group was trained in one of the behavioral tasks used: step-down inhibitory avoidance, two-way active avoidance or habituation to the open field. Twenty-four hours later, the rats were submitted to the surgical procedures, with half of the animals in each group receiving saline and the other half NMDA injections. After one week for recovery, the animals were submitted to the respective test session.

In both experiments, the researcher who collected the behavioral data was blind to the condition of the animals (control or lesioned).

\section{Statistical analysis}

Parametric data are reported as means \pm
SEM and were analyzed by the Student $t$ test. Nonparametric data are reported as median (interquartile range) and were analyzed by the Mann-Whitney U-test.

\section{Results}

\section{Experiment 1: Effect of pretraining lesion of the entorhinal cortex on memory of different tasks}

In the two-way active avoidance task there was no significant difference in training performance between groups $(\mathrm{t}(14)=$ 0.18 ; $\mathrm{P}>0.05$, Student $t$-test). Control animals showed better retention scores when compared to NMDA-lesioned animals ( $\mathrm{t}(14)$ $=2.91 ; \mathrm{P}<0.02$, Student $t$-test) (Figure 2).

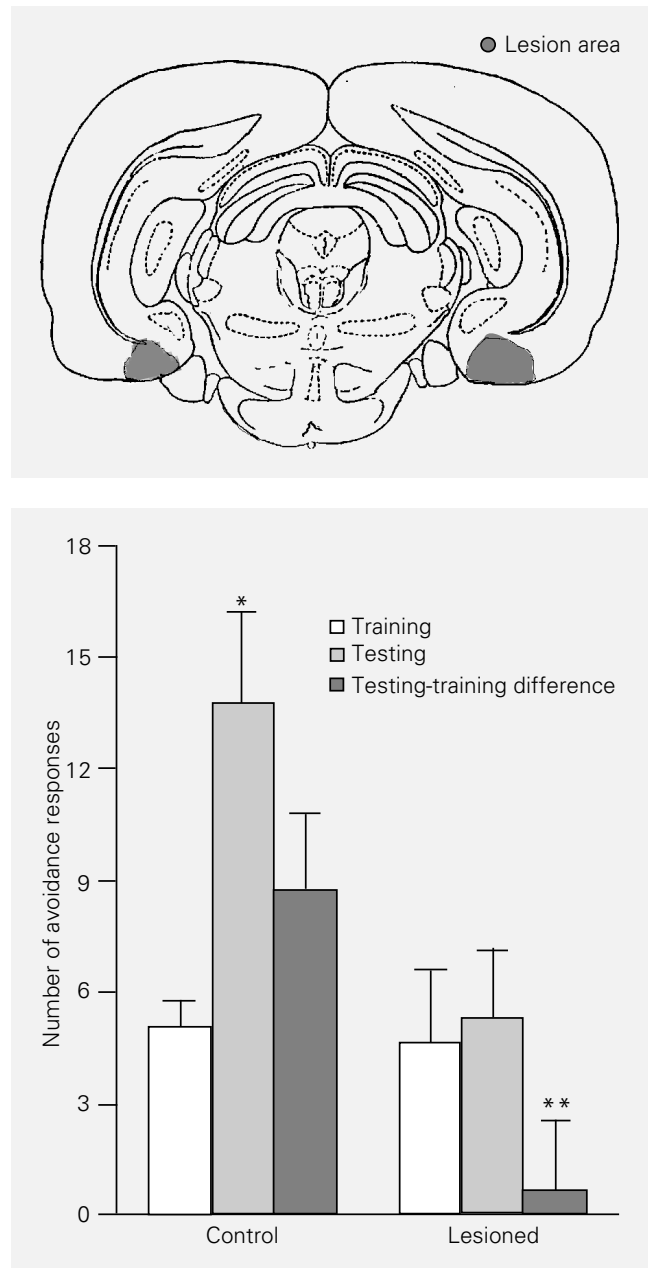

Figure 1 - Drawing of a representative coronal section showing the localization of the lesion (shaded area).
Figure 2 - Effect of a pretraining lesion of the entorhinal cortex on performance in a two-way active avoidance task. Data are reported as means \pm SEM $(\mathrm{N}=8$ animals/group). ${ }^{*} \mathrm{P}<0.005 \mathrm{com}-$ pared to the training session (paired Student $t$-test). ${ }^{*} \mathrm{P}<0.02$ compared to the control group (unpaired Student $t$-test). 
Figure 3 - Effect of a pretraining lesion of the entorhinal cortex on performance in a step-down are reported as median (interquartile range) ( $\mathrm{N}=8$ animals/ group). There were no significant differences between groups ( $P>0.05$, Mann-Whitney U-test).

Figure 4 - Effect of a pretraining lesion of the entorhinal cortex on performance in an open field task. Data are reported as means \pm SEM ( $N=10$ animals/group). There were no significant differences between groups $(P>0.05$, Student $t$-test). ${ }^{*} \mathrm{P}<0.05 \mathrm{com}$ pared to the training session (paired Student $t$-test). inhibitory avoidance task. Data
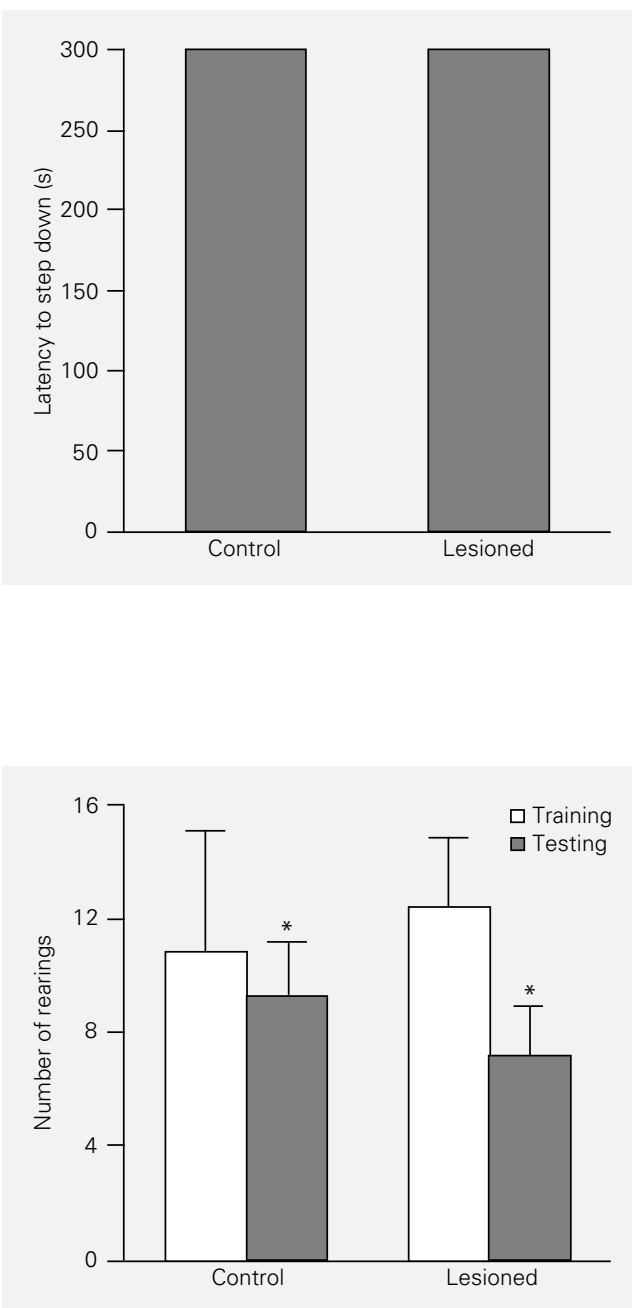

Figure 5 - Effect of a post-training lesion of the entorhinal cortex on performance in a two-way active avoidance task. Data are reported as means \pm SEM $(\mathrm{N}=9$ animals/group). ${ }^{*} \mathrm{P}<0.002 \mathrm{com}$ pared to the training session (paired Student $t$-test). ${ }^{*} \mathrm{P}<$ 0.001 compared to the control group (unpaired Student $t$-test).
Comparison of training and testing sessions showed a significant difference in the control group $(\mathrm{t}(7)=4.27 ; \mathrm{P}<0.005$, Student paired $t$-test), while no difference was found in the NMDA-lesion group $(\mathrm{t}(7)=0.33$; $\mathrm{P}>0.05$, paired Student $t$-test).

In the step-down inhibitory avoidance task there was a significant difference between groups in the training session $(\mathrm{t}(14)=$ 2.80 ; $\mathrm{P}<0.02$, Student $t$-test). The NMDAlesioned group had a lower latency to step down $(3.63 \pm 0.91)$ compared to the saline group $(8.50 \pm 1.49)$. In the testing session, there was no difference in performance between groups $(\mathrm{U}=24.0 ; \mathrm{P}>0.05$, MannWhitney U-test) (Figure 3).

In the habituation to the open field there was no significant difference in training or testing performance between groups $(\mathrm{P}>0.05$, Student $t$-test). Both groups showed a significant difference between training and testing sessions ( $\mathrm{P}<0.05$, paired Student $t$-test), which is interpreted as an adequate memory for the task (Figure 4).

Experiment 2: Effect of post-training lesion of the entorhinal cortex on memory of different tasks

In the two-way active avoidance task there was no significant difference in training performance between groups $(\mathrm{t}(16)=$ 1.65 ; $\mathrm{P}>0.05$, Student $t$-test). Control animals showed better retention scores when compared to NMDA-lesioned animals ( $\mathrm{P}<0.001$, Student $t$-test) (Figure 5). Comparison of training and testing sessions showed a significant difference in the control group $(\mathrm{t}(8)=4.5 ; \mathrm{P}<0.002$, paired Student $t$-test), while no difference was found in the NMDA-lesioned group $(\mathrm{t}(8)=1.96$; $\mathrm{P}>0.05$, paired Student $t$-test).

In the step-down inhibitory avoidance task there was no significant difference between groups in the training session $(\mathrm{t}(14)=$ $1.83 ; \mathrm{P}>0.05$, Student $t$-test). In the testing session there was a significant difference in 
performance between groups $(\mathrm{U}=8 ; \mathrm{P}<0.02$, Mann-Whitney U-test). The NMDA-lesioned group had a lower latency to step down, suggesting a deficit of memory for this task (Figure 6).

In the habituation to the open field there was no significant difference in training or testing performance between groups $(\mathrm{P}>0.05$, Student $t$-test). Both groups showed a significant difference between training and testing sessions ( $\mathrm{P}<0.05$, paired Student $t$-test $)$, which is interpreted as an adequate memory for the task (Figure 7).

\section{Discussion}

The results show that bilateral NMDA lesions of the entorhinal cortex have taskspecific effects on memory. In the two-way shuttle avoidance, memory impairment was observed with both pre- and post-training lesions. In the inhibitory avoidance, only post-training lesions had an amnestic effect, which was far from complete. In this task, pretraining lesions caused a significant difference between groups in the training session, that may have been due to motor impairment, with a consequent alteration in behavior. However, this was not the case, since intertrial crossings in the two-way active avoidance, or crossings in the habituation to the open field presented no difference. Furthermore, in the testing session of inhibitory avoidance there was no difference in performance between groups. In the open field task neither pre- nor post-training lesions had any effect.

The higher sensitivity of the shuttle avoidance task to entorhinal cortex lesions is consistent with the idea that this area may play an integrative role in information processing of successively acquired memories, since this task involves several consecutive trials (4,11,19-21).

The entorhinal cortex could, in principle, be involved in different aspects of memory processing: acquisition, consolidation and

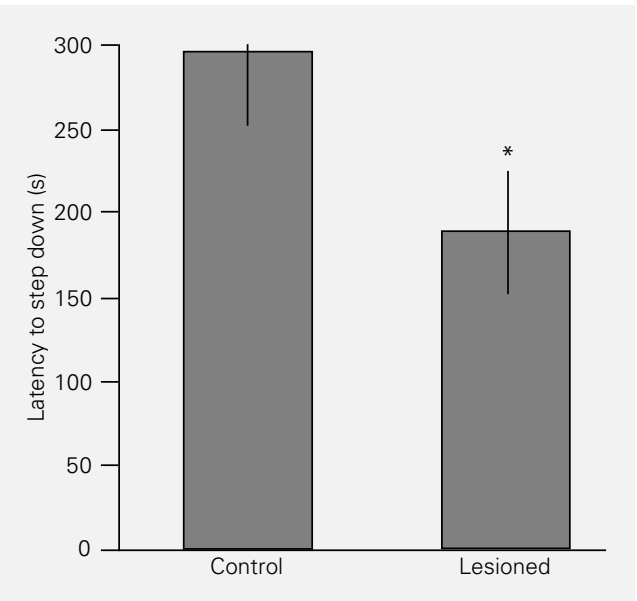

Figure 6 - Effect of a post-training lesion of the entorhinal cortex on performance in a stepdown inhibitory avoidance task. Data are reported as median (interquartile range) ( $\mathrm{N}=8$ animals/ group). ${ }^{*} \mathrm{P}<0.05$ compared to the control group (MannWhitney U-test).

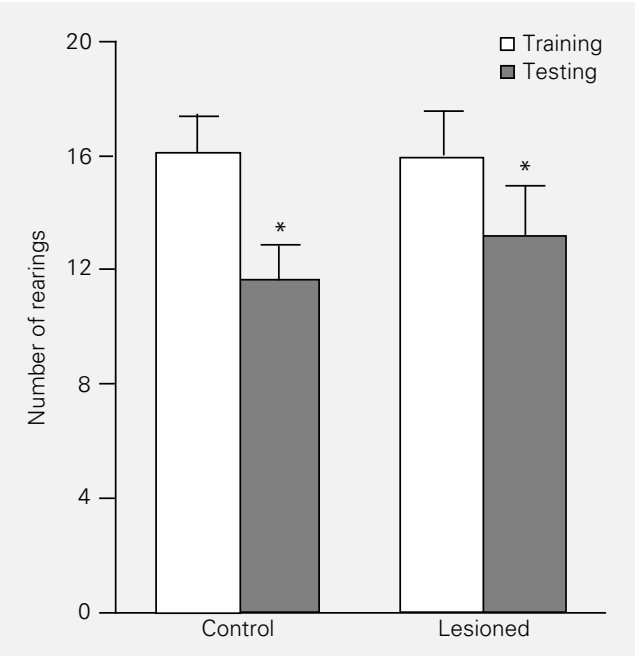

Figure 7 - Effect of a post-training lesion of the entorhinal cortex on performance in an open field task. Data are reported as means \pm SEM ( $N=10$ animals/ group). There were no significant differences between groups ( $P>0.05$, Student $t$-test). ${ }^{*} P<0.005$ compared to the training session (paired Student $t$ test).

retrieval. The impairment of performance in shuttle avoidance caused by pretraining lesions may be due to an effect on any of these phases. The results with post-training lesions suggest that its primary effect might be on consolidation and/or retrieval. Previous studies $(4,10,11)$ have suggested a major role for this structure in late consolidation. Willner et al. (20), however, have shown that the entorhinal cortex does also participate in acquisition, although its role does not become manifest unless this structure is hindered within the late post-training period.

Another way of viewing these findings is that the effect of the NMDA lesions of the entorhinal cortex is correlated with the associative characteristics of the task. In the 
shuttle avoidance paradigm, indeed, the animals must compare the outcome of their past behavior in each consecutive trial; this is needed just once in the inhibitory avoidance task, and is in fact irrelevant in the open field task. Thus, the present data might be considered to support previous findings that suggest a comparator or sorting-out role for the entorhinal cortex at the time of acquisition and retrieval $(20,22)$.

\section{References}

1. Van Hoesen GW, Hyman BT \& Damasio AR (1991). Entorhinal cortex pathology in Alzheimer's disease. Hippocampus, 1: 18.

2. Thompson R (1976). Entorhinal-subicular lesions: amnestic effects on an assortment of learned responses in the white rat. Bulletin of the Psychological Society, 8: 433-434.

3. Zola-Morgan S, Squire LR, Amaral DG \& Suzuki W (1989). Lesions of perirhinal and parahippocampal cortex that spare the amygdala and hippocampal formation produce severe memory impairment. Journal of Neuroscience, 9: 4355-4370.

4. Ferreira MBC, Da Silva RC, Medina JH \& Izquierdo I (1992). Late post-training memory processing by entorhinal cortex: role of NMDA and GABA-A receptors. Pharmacology, Biochemistry and Behavior, 41: 767-771.

5. Glasier M, Chen X, Sutton R \& Stein D (1991). Effects of unilateral entorhinal cortex lesion and GM1 ganglioside treatment on water maze performance. Society for Neuroscience Abstracts, 17: 132.

6. Johnson DL \& Kesner RP (1991). Differential effects of entorhinal cortex and hippocampal lesions on performance of a spatial location recognition. Society for Neuroscience Abstracts, 17: 131.

7. Zola-Morgan S, Squire LR, Clower RP \& Rempel NL (1993). Damage to the perirhinal cortex exacerbates memory impairment following lesions to the hippocampal formation. Journal of Neuroscience, 13: 251-265.

8. Hyman BT, van Hoesen GW \& Damasio AR (1990). Memory related neural systems in Alzheimer's disease: An anatomic study. Neurology, 40: 1721-1730.
9. Witter MP, Groenewegen HJ, Lopes da Silva FH \& Lohman AHM (1989). Functional organization of the extrinsic and intrinsic circuitry of the parahippocampal region. Progress in Neurobiology, 33: 161253.

10. Izquierdo I \& Medina JH (1995). Correlation between the pharmacology of memory and the pharmacology of longterm potentiation. Neurobiology of Learning and Memory, 63: 17-29.

11. Ferreira MBC, Wolfman C, Walz R, Da Silva RC, Zanatta MS, Medina JH \& Izquierdo | (1992). NMDA-dependent, GABA-A-sensitive role of the entorhinal cortex in posttraining memory processing. Behavioral Pharmacology, 3: 387-394.

12. Paxinos G \& Watson C (1986). The Rat Brain in Stereotaxic Coordinates. 2nd edn. Academic Press, Sydney.

13. Cahill L \& McGaugh JL (1990). Amygdaloid complex lesions differentially affect retention of task using appetitive and aversive reinforcement. Behavioral Neuroscience, 104: 532-543.

14. Sananes BC \& Davis M (1992). N-methyl$D$-aspartate lesions of the lateral and basolateral nuclei of the amygdala block fear, potentiate startle and shock sensitization startle. Behavioral Neuroscience, 106: 72-80.

15. Bianchin M, Walz R, Ruschel AC, Zanatta MS, Da Silva RC, Bueno e Silva M, Paczko N, Medina JH \& Izquierdo I (1993). Memory expression is blocked by the infusion of CNOX into the hippocampus and/or amygdala several days after training. Behavioral and Neural Biology, 59: 83-86.
16. Pereira ME, Rosat RM, Huang $\mathrm{CH}$, Godoy MG \& Izquierdo I (1989). Inhibition by diazepam of the effect of additional training and extinction on the retention of shuttle avoidance behavior in rats. Behavioral Neuroscience, 103: 202-205.

17. Izquierdo I (1979). Effect of naloxone and morphine on various forms of memory in the rat: possible role of endogenous opiate mechanisms in memory consolidation. Psychopharmacology, 66: 199-203.

18. Netto CA \& Maltchik M (1990). Distinct mechanisms underlying memory modulation after the first and the second session of two avoidance tasks. Behavioral and Neural Biology, 53: 29-38.

19. Izquierdo I (1992). The neurobiology of memory consolidation. Neuroscience, 18: 1-11.

20. Willner $P$, Bianchin $M$, Walz R, Bueno e Silva M, Zanatta MS \& Izquierdo I (1993). Muscimol infused into the entorhinal cortex prior to training blocks the involvement of this area in post-training memory processing. Behavioral Pharmacology, 4: 95-99.

21. Zola-Morgan S (1990). The neuropsychology of memory. Annals of the New York Academy of Sciences, 608: 434-456.

22. Jerusalinsky D, Quillfeldt JA, Walz R, Da Silva RC, Bueno-e-Silva M, Bianchin M, Zanatta MS \& Ruschel AC (1994). Effect of the infusion of the GABA-A receptor, muscimol, on the role of the entorhinal cortex, amygdala and hippocampus on memory processes. Behavioral and Neural Biology, 62: 132-138. 